\title{
Geostrophic transport in the Warm Water Sphere of the eastern subtropical North Atlantic
}

\author{
by Lothar Stramma ${ }^{1}$
}

\begin{abstract}
Geostrophic transports in the eastern subtropical North Atlantic computed from historic hydrographic data and recent CTD measurements show a mean transport in the subtropical gyre of $11 \pm 1.5 \times 10^{6} \mathrm{~m}^{3} \mathrm{~s}^{-1}$ in the upper $1000 \mathrm{~m}$ between $35 \mathrm{~W}$ and the African coast. The dynamic method was used in conjunction with a conservation of mass scheme (Fiadeiro and Veronis, 1982) to determine the level of no motion. This level lies in the $1200 \mathrm{~m}$ depth near the Azores and drops to $1500 \mathrm{~m}$ in the tropics.

The main inflow enters south of the Azores as a relatively narrow current, turns southward at the latitude of Madeira and then widens. Three current bands transport the water southward. North of the Cape Verde Islands, the current turns westward. This part of the North Equatorial Current extends more to the south in the upper $200 \mathrm{~m}$ than in the $200-800 \mathrm{~m}$ layer. The Portugal current, between the Azores and the Portuguese coast, which is thought by some to be strong, is seen here as a relatively weak flow.

Maps of potential vorticity derived from smoothed density profiles are consistent with the general pattern of geostrophic transport.
\end{abstract}

\section{Introduction}

Today there still exists no clear determination of where the return flow in the eastern North Atlantic takes place. Several investigations were carried out in the North Atlantic to estimate the gyre circulation transports. Many observations were made in the western Atlantic where the Gulf Stream gives a clear signal, but data are sparse in the eastern Atlantic where weak currents and small signals dominate. There exist contradicting opinions as to which part of the total transport of the subtropical gyre takes place in the eastern Atlantic. This paper attempts to give a rough estimate of the geostrophic transports in the Warm Water Sphere (i.e., the depth range of the surface layer and main thermocline) of the subtropical North Atlantic east of $35 \mathrm{~W}$.

Early investigators expected an Atlantic-wide circulation with a broad return flow at the European and African coasts. In a study of the area between the Azores and the Portuguese coast, Sverdrup et al. (1942) computed a southward transport in the central and subarctic water masses of $14 \times 10^{6} \mathrm{~m}^{3} \mathrm{~s}^{-1}$ east of the Azores and $4 \times 10^{6} \mathrm{~m}^{3} \mathrm{~s}^{-1}$ off Portugal, with a reference at the $7^{\circ}$-isotherm. Similarly high

1. Institut für Meereskunde, Düsternbrooker Weg 20, 2300 Kiel, Federal Republic of Germany. 
transports were obtained by Dietrich et al. (1980) from the International Geophysical Year (IGY) data of the North Atlantic. Between the Azores and Portugal he found a transport of $14 \times 10^{6} \mathrm{~m}^{3} \mathrm{~s}^{-1}$ between the surface and 1000 meters. $4 \times 10^{6} \mathrm{~m}^{3} \mathrm{~s}^{-1}$ of this transport is located near the European coast and called the Portugal Current. These results are in agreement with many surface current charts, which show a broad southward component east of the Azores (Schumacher, 1940).

Recent investigations have shown that the transport in the eastern North Atlantic is small compared to that of the western North Atlantic. Worthington (1976) states that the circulation system of the North Atlantic consists of two gyres in the western Atlantic. The transport only takes place in the western and central part of the Atlantic and the eastern Atlantic contributes less than $10 \times 10^{6} \mathrm{~m}^{3} \mathrm{~s}^{-1}$.

Saunders (1982), used density data from IGY sections in the eastern Atlantic which were averaged basin-wide for all standard depths to estimate the best density gradient in the least squares sense. The absolute velocity in each section had been chosen so that the transport satisfied the Sverdrup relation. For the depth range 0-850 m, Saunders computed a southeastward transport of the order $3-4 \times 10^{6} \mathrm{~m}^{3} \mathrm{~s}^{-1}$ between the Azores and Portugal. South of the Azores 6-7 $\times 10^{6} \mathrm{~m}^{3} \mathrm{~s}^{-1}$ enter the eastern Atlantic. Evidence for a strong eastward current south of the Azores is included in some former papers (eg., Ekman, 1923; Jacobsen, 1929; Stommel et al., 1978). This can also be seen in a map of potential density at $200 \mathrm{~m}$ derived from data obtained during the $F . S$. Meteor cruise 1925-1927 (Wüst, 1936).

In geostrophic computations there is always the problem of relating relative to absolute velocity. Predominantly the problem is to find a level of no motion. Up to now there exists no method to find that depth, assuming it exists. Defant (1941) suggested that the level of no motion be taken where the vertical gradient of the geopotential anomaly difference between two stations is zero or nearly zero.

New developments on this subject are the $\beta$-spiral method (Stommel and Schott, 1977 ) and the inverse method (Wunsch, 1977, 1978). The basic equations for the $\beta$-spiral are the thermal wind equation, density conservation and the potential vorticity equation. With this method there is a tendency for the reference velocities to depend on the depth range of the data used. Behringer and Stommel (1980) solved this problem using data collected especially for the $\beta$-spiral calculation.

The inverse method also uses the thermal wind equation and density conservation as well as incompressibility. In areas with strong currents, for example in the Carribean Sea, the results are good (Roemmich, 1981). In the eastern Atlantic, where the currents are weak, Wunsch and Grant (1982) found some unrealistic transports.

Using wind stress data from the central Atlantic in March and October, Hellerman (1980) computed transports in the North Equatorial Current (NEC) using the Sverdrup relation. He found that at $23 \mathrm{~W}$, the NEC transports $10 \times 10^{9} \mathrm{~kg} \mathrm{~s}^{-1}$ in March and $3 \times 10^{9} \mathrm{~kg} \mathrm{~s}^{-1}$ in October. At $38 \mathrm{~W}$, the NEC transports $23 \times 10^{9} \mathrm{~kg} \mathrm{~s}^{-1}$ in March and $9 \times 10^{9} \mathrm{~kg} \mathrm{~s}^{-1}$ in October. 
In this paper, transports are computed from hydrographic data from the subtropical eastern North Atlantic, using the traditional level of no motion. However, several criteria to determine this level of no motion are combined.

\section{The data set}

An edited data set was prepared from historic hydrographic data from the eastern Atlantic archived at the World Oceanographic Data Center (WODC) A in 1980 for the computation of $T / S$-curves in the eastern subtropical Atlantic (Siedler and Stramma, 1983). Only stations including data deeper than $100 \mathrm{~m}$ were considered near the African coast to exclude shallow shelf water samples. Stations with dubious data, apparent from spikes or systematic deviations, were rejected. The data set was again edited by eliminating all profiles which differed considerably from the mean profiles. For the region 8 to $41 \mathrm{~N}$ and east of $35 \mathrm{~W}, 2987$ of the 4385 stations were retained. Within $783^{\circ} \times 3^{\circ}$ squares in the eastern Atlantic, mean profiles of temperature, salinity, density, and dissolved oxygen were produced. The chosen depth intervals were $2 \mathrm{~m}$ in the top $100 \mathrm{~m}, 10 \mathrm{~m}$ from $100 \mathrm{~m}$ to $1500 \mathrm{~m}$ and $50 \mathrm{~m}$ below $1500 \mathrm{~m}$. The data were then smoothed with a moving average producing strong smoothing in the upper ocean and weak smoothing in the deep ocean, where the data scatter was small.

In addition to the above archived data, observations made during cruise number 60 of the F.S. Meteor in March-April, 1982 (Fig. 1) were used. These observations supplement the archived data well by providing data coverage where observations were extremely sparse. They are analyzed separately to compare the results of the mean profiles with a quasi-synoptic spring data set.

\section{The level of no motion}

The dynamic method is burdened with the problem of finding an integration reference, commonly called the "level of no motion." Although there are new methods to compute the geostrophic flow such as the $\beta$-spiral and the inverse method, the problem of finding the absolute velocities is not yet completely solved. Also, there are criticisms of these new methods (Keffer and Niiler, 1982; Luyten and Stommel, 1982). This study attempts to improve the determination of the geostrophic flow using results from classical methods, a review of which is given in Fomin (1964).

It would be unrealistic to expect that a permanent surface exists wherein the velocities are zero. But one can identify a low velocity layer, which, when used as an integration reference, yields reasonably accurate transports in the Warm Water Sphere.

Geopotential anomalies were computed from density profiles averaged within $3^{\circ} \times$ $3^{\circ}$ squares. The differences of the anomalies were plotted for all neighboring $3^{\circ} \times 3^{\circ}$ squares and the vertical gradients of the difference profiles were computed to find all possible reference depths via Defant's method. These depths should be indicated by 


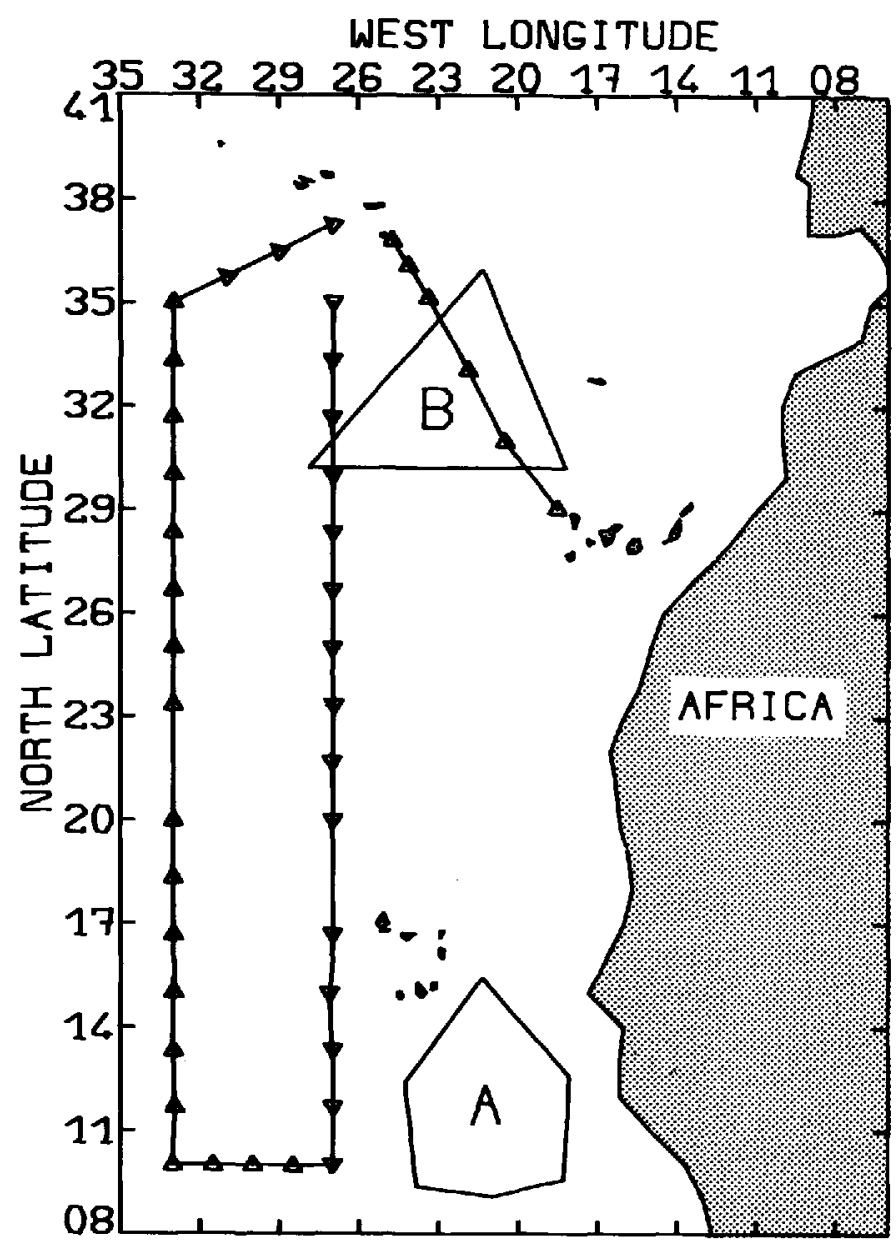

Figure 1. Locations of the CTD profiles (triangles) from the March-April, 1982 cruise of the F.S. Meteor. A and B denote two regions where conseryation of mass computations were made.

zero or low vertical geopotential anomaly gradients. Figure 2 shows the curves of the difference of three neighboring mean profiles. Two profiles show a low vertical gradient below $1500 \mathrm{~m}$, and the third profile between $1100 \mathrm{~m}$ and $1800 \mathrm{~m}$. At greater depths the probable computational error will be comparable to the computed anomalies for small velocities. Consequently, several of the produced profiles show the influence of the error at depths greater than $2000 \mathrm{~m}$. Defant's method yields a couple of possible reference depths. In order to distinguish between them, it was demanded that the low vertical geopotential gradient should persist over more than $50 \mathrm{~m}$, and a low gradient should be at nearly the same depth for neighboring station pairs. The 
$\Delta D, m^{2},-2$

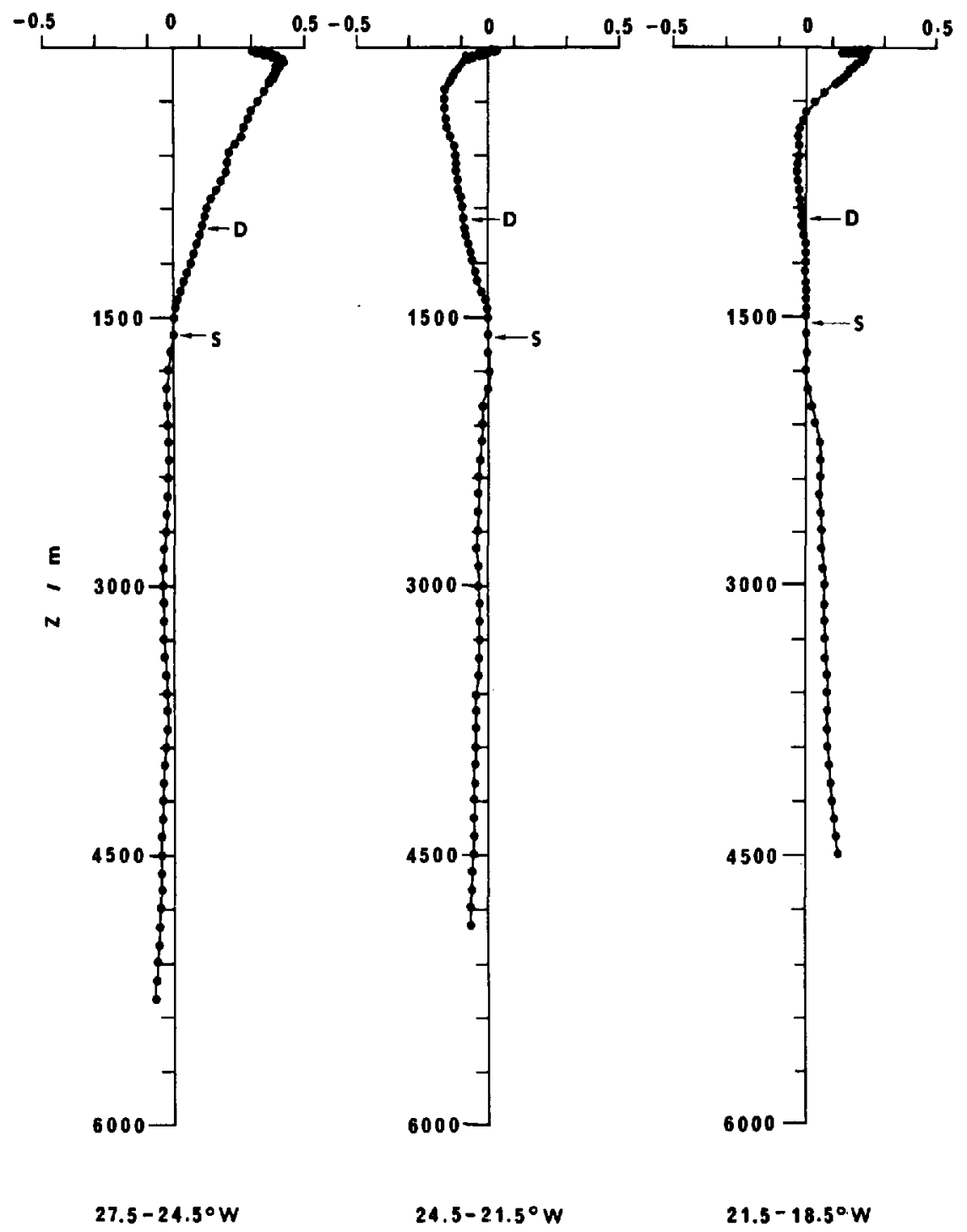

Figure 2. Differences of the geopotential anomalies from mean $3^{\circ} \times 3^{\circ}$ square profiles along 9.5N between 18.5W and 27.5W. D indicates reference depth used by Defant, $\mathrm{S}$ indicates reference depth used here. 
depths of the oxygen and salinity maxima and minima and the water mass distribution in this region were also considered. As the salinity maxima and minima should be conserved by advection the reference depth computed by Defant's method should not intersect them. Using this criterion, the subjective analysis reduced the number of possible reference depths to two. In the region south of the Azores the best choice was a reference depth at about $1200 \mathrm{~m}$. It was often possible to choose a level at about $800 \mathrm{~m}$ near the oxygen minimum, which could be an indicator of a region of low velocity. Defant's method applied to data from the tropics yields reference levels at $1300 \mathrm{~m}$ to $1500 \mathrm{~m}$ and sometimes also at $500 \mathrm{~m}$ to $700 \mathrm{~m}$, but normally the eastward and southward velocity components do not simultaneously indicate the latter (for example, Fig. 2).

As an adjunct to the above analysis, the result of mass conservation computations were used to fix the reference depth. Taking the density distribution along the border of a closed area of ocean and using the equation of conservation of mass, one can determine possible reference depths. Fiadeiro and Veronis (1982) (hereafter refered to as FV), for example, used an empirical search procedure based only on hydrographic data and the use of the dynamical method to get a good estimate of the level of no motion for the Tasman-Coral sea. Their criterion was to select the level that yields the minimum mean square transport imbalances for a set of carefully chosen independent layers. Their volume flux technique has been discussed in detail in their paper; the following is a brief summary of their method applied to mass flux. The hydrostatic and geostrophic balance yields the thermal wind relation

$$
\frac{\partial}{\partial z} \rho v=-\frac{g \partial \rho}{f \partial x} .
$$

The velocity $v_{r}$ relative to the level $z_{r}$ where $v$ is assumed to vanish is then

$$
v_{r}=-\frac{g}{\rho f} \int_{z_{r}}^{z} \frac{\partial p}{\partial x} d z
$$

The velocity field can then be used to determine the mass flux within any layer between two stations. The total mass flux for the $j=1, \ldots, F$ layers is given by

$$
T_{r j}=\int_{0}^{L} \int_{z_{j+1}}^{z_{j}} \rho v_{r} d z d x
$$

where $z_{j}$ is the level of the top of the $j$-th layer and $L$ is the perimeter of the closed area. For data grided at $n$ discrete horizontal locations, $i=1, \ldots, n$, the horizontal integral is approximated by a finite sum

$$
T_{r j}=\sum_{i=1}^{n} \int_{z_{j+1}}^{z_{j}} \rho_{i} v_{r i} d z \Delta_{i} x
$$

where $\Delta_{i} x=x_{i+1}-x_{i}\left(\Delta_{n} x=x_{1}-x_{n}\right)$ and $v_{r i}$ is evaluated at the midpoint of $\Delta_{i} x$. Here 
the vertical integral $v_{r i}$ and $\rho_{i}$ are evaluated at $5 \mathrm{~m}$ intervals from $5 \mathrm{~m}$ to the bottom, and the vertical integral is also approximated by a discrete sum. Ideally, a level of no motion is found by varying $z_{r}$ until $T_{r j}$ vanishes. However, noise in the data and the possibility that no level of zero motion exists prevent $T_{r j}$ from being exactly zero in practice. FV imposed the criterion that the mean square transport residual

$$
T_{r}^{2}=\sum_{j=1}^{F} T_{r j}^{2}=\min
$$

is minimum at the level of no motion.

This study applies their method to data from the eastern North Atlantic. Both volume and mass transports were computed, but the resulting deviations differed by less than $10 \%$. In the following, only the results of mass transport calculations are presented.

To find the possible conservative layers, features like dissolved oxygen, salinity, potential density and potential vorticity were examined and surfaces with constant values of potential density relative to $3000 \mathrm{~m}, \sigma_{3}$, were chosen to determine the boundaries between the layers. Potential vorticity, here computed as $f \cdot\left(\partial \sigma_{3} / \partial z\right)$, was evaluated with a smooth spline function and finite differencing over an interval of $10 \mathrm{~m}$.

Four layers were used. The average thicknesses of the layers were made comparable so that none of them really dominates, and the upper layer was chosen to contain most of the Warm Water Sphere to exclude nonconservative transport processes. The deeper layers were divided by the oxygen maxima caused by the Middle North Atlantic Deep Water and the Lower North Atlantic Deep Water. These maxima occurred with potential vorticity minima. The bottom of the upper layer was taken at the oxygen minimum at about $800 \mathrm{~m}$ in the northern region and at the salinity minimum of the South Atlantic Intermediate Water in the tropical region. These maxima and minima will be conserved if the concurrent vertical velocity is small.

A test was made with layers separated by potential density values at depths between the extrema. The resulting transport imbalances $T_{r}^{2}$ were up to $50 \%$ greater for small values of $z_{r}$ and nearly the same for greater $z_{r}$ values. Fiadeiro and Veronis (1983) have shown that the results are influenced by the extrapolation of the velocities from the last observed level to the bottom.

Because of the rough bottom topography, the large distances between the profiles and the negligible gradient of $\sigma_{3}$ at great depths, a depth about $200-400 \mathrm{~m}$ above the sea floor was chosen for the lower limit of the bottom layer. In addition, the depth of the level of no motion can change over small distances. Therefore, the closed areas were chosen in such a way that the distance between any two vertices was less than $1000 \mathrm{~km}$. The resultant mean square transport imbalances $T_{r}^{2}$ versus reference depths $z_{r}$ are presented in Figure 3 for a tropic area (area A in Fig. 1) and in Figure 4 for a subtropic area (area B in Fig. 1). The summation of the net transport of the 4 layers $T$, is also shown in these figures. 


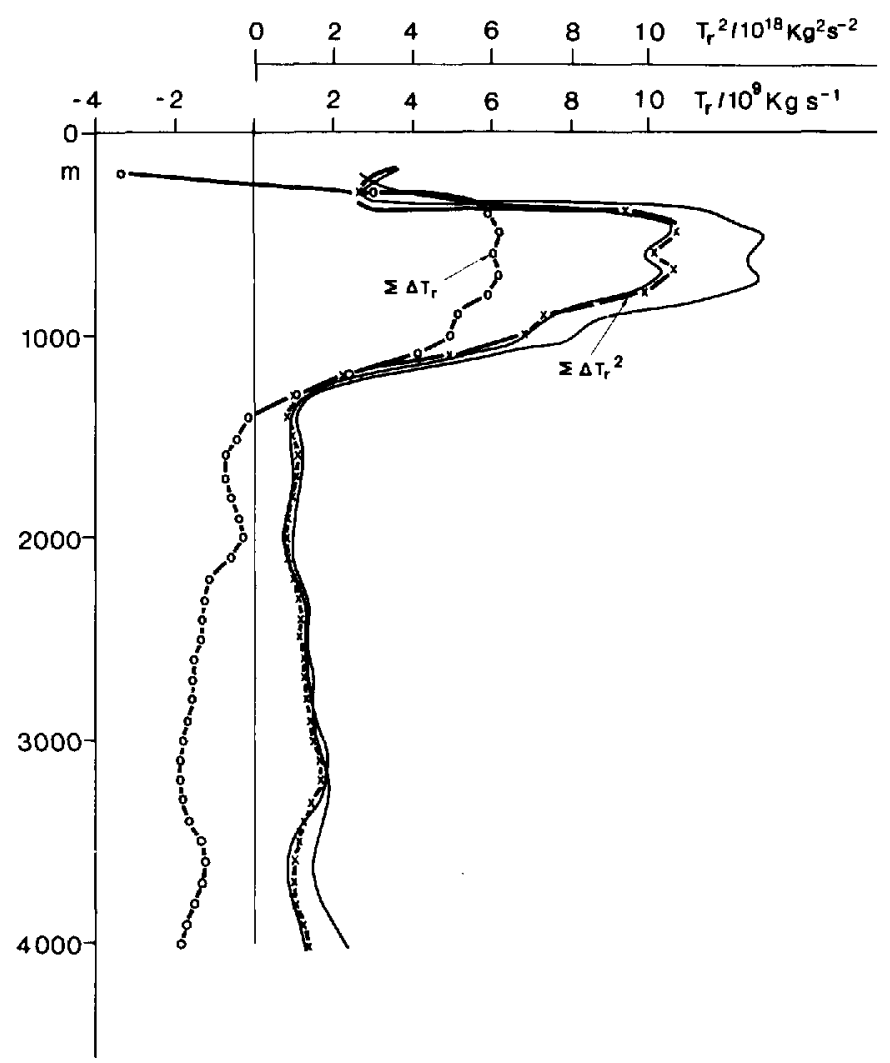

Figure 3. Mean square transport imbalances $T_{r}^{2}$ (in $10^{18} \mathrm{~kg}^{2} \mathrm{~s}^{-2}$ ) (crosses) and mean transport imbalances $T_{r}$ (in $10^{9} \mathrm{~kg} \mathrm{~s}^{-1}$ ) (circles) vs. reference depth from the tropical area "A" (Fig. 1). Solid lines are two $T_{r}^{2}$-curves derived from the noise simulating data set.

In the calculation of the transport imbalances, a number of closed areas were selected and means of the $3^{\circ} \times 3^{\circ}$ square profiles were computed. For every closed area, the potential density of the minima and maxima were computed to separate the conservative layers. Following FV, a test of the effect of noise by adding random errors to the data was made. Typical instrument precisions of $0.02^{\circ} \mathrm{C} ; 0.005 \%$; and $0.5 \%$ of the depth were multiplied by randomly selected numbers between -1 and +1 and then added to the mean profiles of temperature and salinity. The altered profiles were then used to compute transport imbalances, which differed by less than $10 \%$ from the transport imbalances derived from the original temperature and salinity profiles. The squares of the transport imbalance $T_{r}^{2}$ show typical differences of $20 \%$, which could reach higher values for large $T_{r}^{2}$ values. Two examples are presented in Figures 3 and 4.

It can be seen that there is no distinct minimum in $T_{r}^{2}$ and no convincing zero of $T_{r}$, but a large area with $T_{r}$ near zero and $T_{r}^{2}$ small. This contrasts with the FV findings 


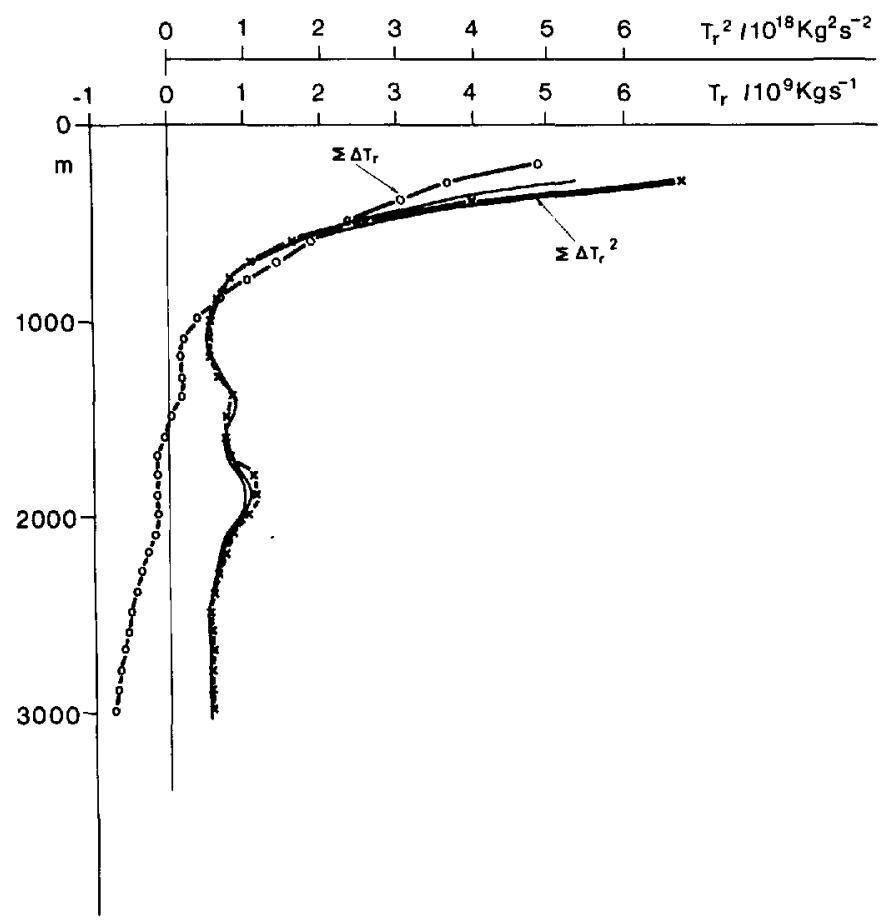

Figure 4. Mean square transport imbalances $T_{r}^{2}$ (in $10^{18} \mathrm{~kg}^{2} \mathrm{~s}^{-2}$ ) (crosses) and mean transport imbalances $T_{r}$ (in $10^{9} \mathrm{~kg} \mathrm{~s}^{-1}$ ) (circles) vs. reference depth from the subtropical area "B" (Fig. 1). Solid lines are two $T_{r}^{2}$-curves derived from the noise simulating data set.

(their Fig. 3). An explanation for this is that the closed areas analyzed in this study were considerably smaller than that analyzed by FV. Thus, the velocity profiles in this study did not differ as much from one side of an area to the other, particularly at greater depths.

The tropic area (Fig. 3) contains 6 mean profiles. Four density layers were used with the boundaries at three density surfaces: $\sigma_{3}=40.73(\sim 820 \mathrm{~m}) ; \sigma_{3}=41.37(\sim 2100 \mathrm{~m})$; $\sigma_{3}=41.48(\sim 3100 \mathrm{~m})$; and the $4000 \mathrm{~m}$ depth.

Figure 3 shows a minimum of $T_{r}^{2}$ at $1200 \mathrm{~m}$ and a zero-crossing of the transport imbalance sum $T$, near $1200 \mathrm{~m}$. Near $2000 \mathrm{~m}$, both curves indicate another possible reference depth. An important result illustrated in this figure is that large transport imbalances occur in the range $500 \mathrm{~m}$ to $700 \mathrm{~m}$ and therefore a reference at these depths, one of the two possibilities of Defant's method, should not be chosen. The same result was found for the other closed regions in the tropics. Furthermore the southward decline in salinity in the salinity minimum indicates that there must be a northward flow of South Atlantic Intermediate Water (SAI), and a reference around $800 \mathrm{~m}$ is therefore not possible.

The subtropical area (Fig. 4), constructed of 3 mean profiles, was divided into 4 


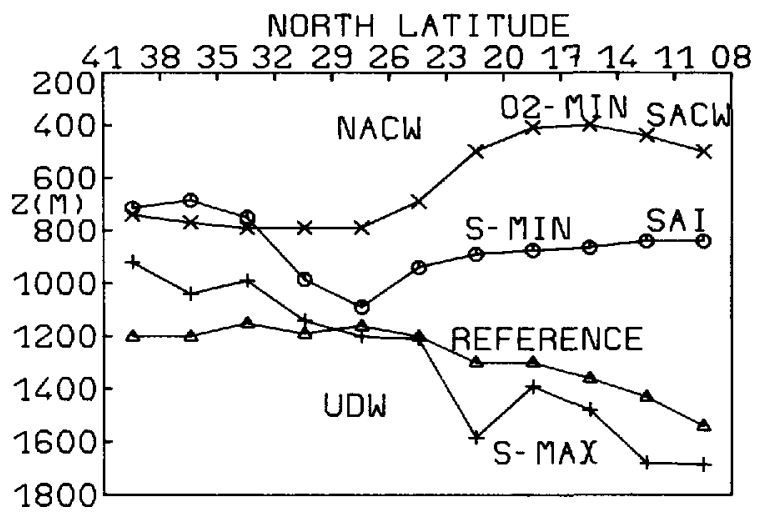

Figure 5. Distribution of water properties from mean profiles along $24^{\circ} 30^{\prime} \mathrm{W}$, from $9^{\circ} 30^{\prime} \mathrm{N}$ to $39^{\circ} 30^{\prime} \mathrm{N}$. Oxygen minima (crosses), salinity minima (circles), salinity maxima $(+)$ and reference depths (triangles) are presented. SACW $=$ South Atlantic Central Water, NACW = North Atlantic Central Water, SAI = South Atlantic Intermediate Water, UDW = Upper Deep Water.

layers with the boundaries at 3 density surfaces: $\sigma_{3}=40.5(\sim 850 \mathrm{~m}) ; \sigma_{3}=41.26$ $(\sim 1715 \mathrm{~m}) ; \sigma_{3}=41.48(\sim 2800 \mathrm{~m})$ and the $4500 \mathrm{~m}$ depth. In the subtropical area (Fig. 4) a minimum of $T_{r}^{2}$ is found at $1150 \mathrm{~m}$ and comparably small values occur below $2400 \mathrm{~m}$. The sum $T$, has nearly zero values from $1100 \mathrm{~m}$ to $2000 \mathrm{~m}$ and a zero-crossing at $1540 \mathrm{~m}$. Considering noise in the data, a choice of a reference at $1200 \mathrm{~m}$ seems to be reasonable and, in any case, is much better than at $800 \mathrm{~m}$, the second possibility by using Defant's method. This result was typically (but not always) found in the subtropical area and thus a reference for the eastern subtropical Atlantic was chosen near $1200 \mathrm{~m}$.

This method did not reveal a reference level in the Atlantic as prominantly as FV's level in the Pacific, but it yielded a means of discriminating between plausible and implausible reference depths.

In the area near the Azores it was often possible to choose a level at about $800 \mathrm{~m}$ using Defant's method. The advantage of such a reference depth is to avoid passing through the salinity maximum of the Mediterranean Water in the south (Fig. 5). The disadvantage of this layer, however, is that the separation between the salinity maximum and minimum is very small, and the eastward component of the current has a strong gradient in some cases at this depth.

In the tropics, mass conservation enables a distinction to be made; in this case the 1300-1500 m depth located between the Upper Deep Water, transporting salty Mediterranean Water to the south, and the SAI and the South Atlantic Central Water, transporting low salinity water to the North, is chosen (Fig. 5).

The chosen reference depth for the level of no motion via Defant's method fixed with FV's method in some regions (Fig. 6) is located at $1500 \mathrm{~m}$ in the tropics and climbs to $1200 \mathrm{~m}$ in the subtropics. This result is contrary to that found by Defant (1941). His 


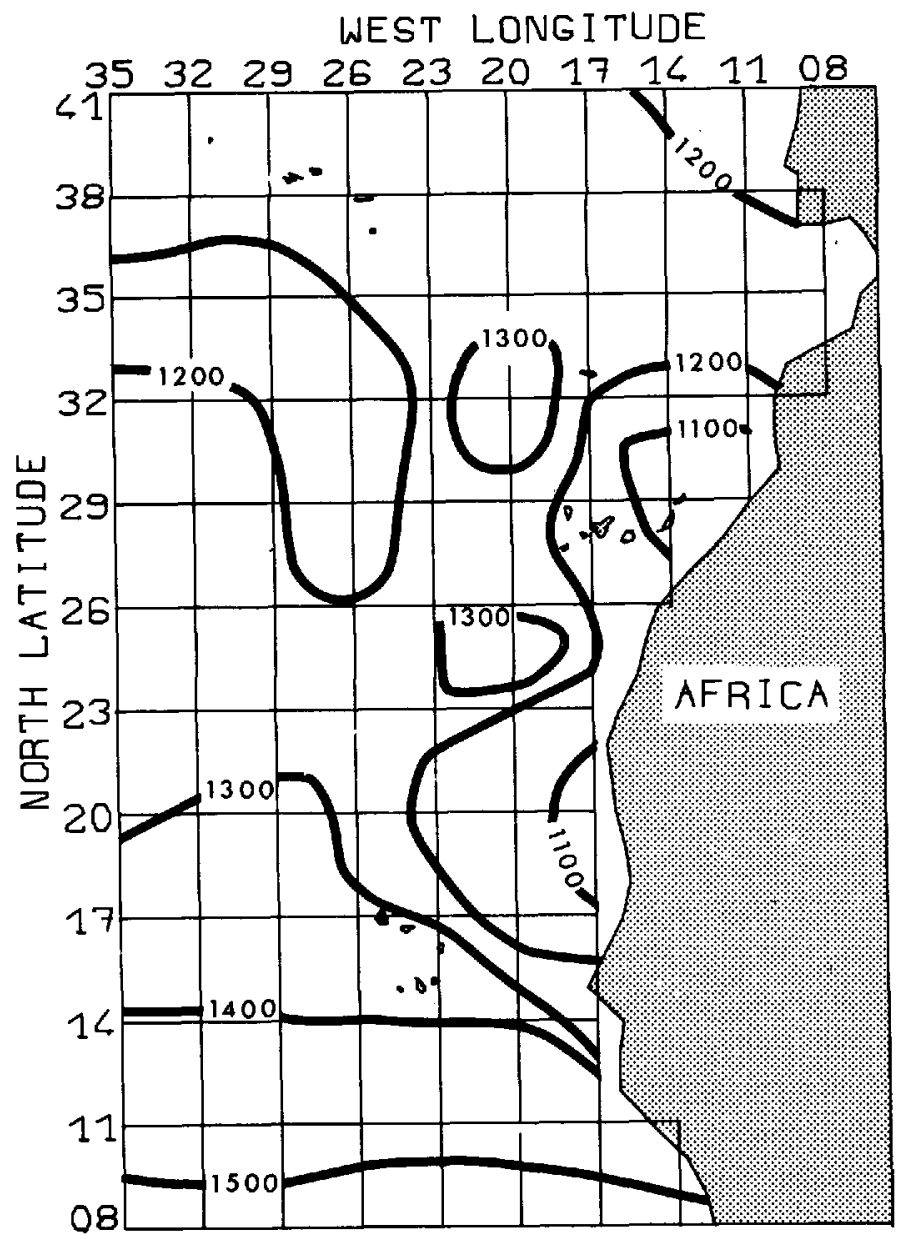

Figure 6. Area of investigation, showing the $3^{\circ} \times 3^{\circ}$ data averaging grid and depth contours of the level of no motion in $\mathrm{m}$.

reference was at $550 \mathrm{~m}$ west of the Cape Verde Islands, descending to $1400 \mathrm{~m}$ near the Azores.

\section{Geostrophic transports}

a. Geostrophic transports from historic data. Geostrophic computations from the $3^{\circ} \times 3^{\circ}$ mean profiles were made using the references illustrated in Figure 6 . The transport in the upper $800 \mathrm{~m}$ is presented in Figure 7 . These contours were prepared and smoothed with an objective analysis scheme developed by Hiller and Käse (1983). As the correlation scale was not known, a value of $470 \mathrm{~km}$ was arbitrarily chosen, which is about 1.4 times the length between the mean profiles and is a scale larger than the eddy scale. The error variance was chosen to be $15 \%$ of the total variance. A second 


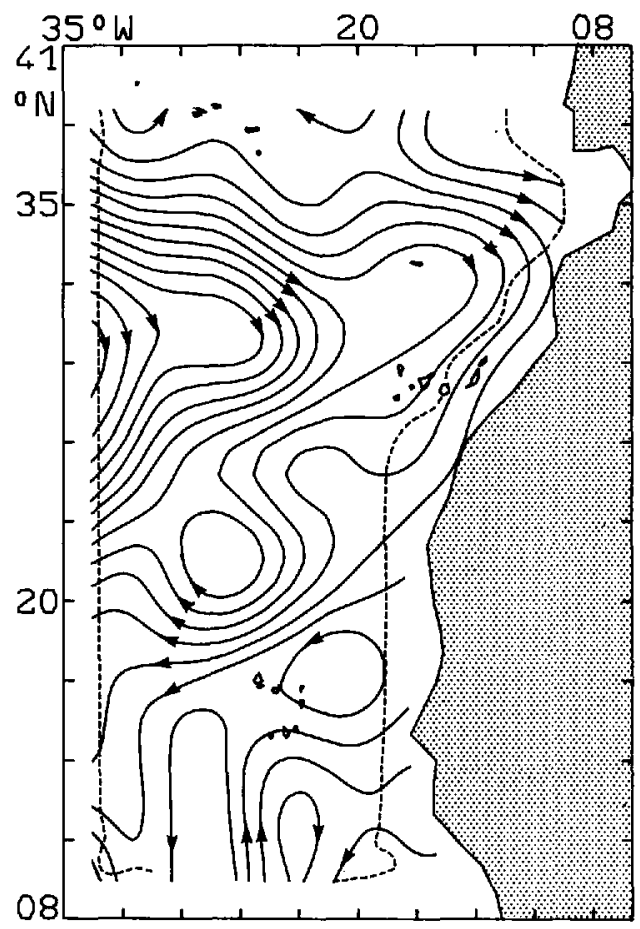

Figure 7. Integrated volume transport $(0$ to $800 \mathrm{~m})$ from mean density profiles with the reference shown in Figure 6. Each flow line represents $10^{6} \mathrm{~m}^{3} \mathrm{~s}^{-1}$.

map derived with a correlation scale of $400 \mathrm{~km}$ and an error variance of $10 \%$ produced nearly the same transport field in the subtropical gyre, while the transport field in the tropics was changed. The error field computed with the objective analysis scheme shows error values higher than $1 \times 10^{6} \mathrm{~m}^{3} \mathrm{~s}^{-1}$ between the border of Figure 7 and the broken line. The transports in the upper $800 \mathrm{~m}$ (Fig. 7) show a Portugal Current transporting around $3 \times 10^{6} \mathrm{~m}^{3} \mathrm{~s}^{-1}$ southward. The zonal transport to the east along $33 \mathrm{~W}$, near $35 \mathrm{~N}$, is of the order of $11 \times 10^{6} \mathrm{~m}^{3} \mathrm{~s}^{-1}$. Most of this inflow of $11 \times 10^{6} \mathrm{~m}^{3} \mathrm{~s}^{-1}$ turns to the south in the central east Atlantic, but a small amount reaches the near coastal region and feeds the Canary Current, while the Portugal Current turns toward the Mediterranean Sea. A transport of $2 \times 10^{6} \mathrm{~m}^{3} \mathrm{~s}^{-1}$ seems to enter the Mediterranean Sea. Dietrich et al. (1980) computed an inflow of $1.75 \times 10^{6} \mathrm{~m}^{3} \mathrm{~s}^{-1}$. At $30 \mathrm{~N}$ three current bands transport the water southward. The current bands are separated by Madeira and the Hyeres- and Meteor Seamounts near $30 \mathrm{~N} 28 \mathrm{~W}$. A large portion of the water of the subtropical gyre leaves the region north of $20 \mathrm{~N}$.

b. Azores-Portugal section. As mentioned above, earlier investigations found southward transports on the order of $14 \times 10^{6} \mathrm{~m}^{3} \mathrm{~s}^{-1}$ between the Azores and the Portugese coast. This transport is considerably larger than that found by Saunders (1982), who calculated a southward trasport from 0 to $850 \mathrm{~m}$ of $2.5 \times 10^{6} \mathrm{~m}^{3} \mathrm{~s}^{-1}$ at $41.5 \mathrm{~N}$. This 
Table 1. Integrated meridional transport in $10^{6} \mathrm{~m}^{3} \mathrm{~s}^{-1}$ between the Azores and Portugal. Negative transport is to the south.

\begin{tabular}{ccccc} 
Reference & \multicolumn{2}{c}{$\begin{array}{c}\text { from mean density profiles } \\
39^{\circ} 30^{\prime} \mathrm{N}, 27^{\circ} 30^{\prime}-12^{\circ} 30^{\prime} \mathrm{W}\end{array}$} & $\begin{array}{c}\text { from R.V. Crawford } \\
40^{\circ} 15^{\prime} \mathrm{N}, 27^{\circ} 58^{\prime}-12^{\circ} 09^{\prime} \mathrm{W}\end{array}$ \\
& & & & \\
$(\mathrm{m})$ & $0-1000 \mathrm{~m}$ & $0-2000 \mathrm{~m}$ & $0-1000 \mathrm{~m}$ & $0-2000 \mathrm{~m}$ \\
800 & -3.1 & -5.6 & -2.6 & -4.1 \\
1000 & -2.8 & -5.1 & -2.9 & -7.1 \\
1200 & -1.5 & -2.5 & -4.6 & -4.3 \\
1500 & +0.1 & +0.7 & -0.6 & -0.0 \\
2000 & +0.1 & +0.8 & -0.6 & -0.8
\end{tabular}

investigation found transports comparable to Saunders findings. Southward transport in the upper $1000 \mathrm{~m}$ across $39^{\circ} 30^{\prime} \mathrm{N}$ inferred from the averaged density profiles is less than $3.2 \times 10^{6} \mathrm{~m}^{3} \mathrm{~s}^{-1}$ (Table 1). The transport is maximal when an $800 \mathrm{~m}$ reference is chosen and decreases with deeper references. A small northward transport is found with reference levels deeper than $1400 \mathrm{~m}$, an unrealistic result considering the distribution of water masses. For comparison, the transports inferred from the R.V. Crawford IGY section along $40^{\circ} 15^{\prime} \mathrm{N}$, between $27^{\circ} 58^{\prime} \mathrm{W}$ and $12^{\circ} 09^{\prime} \mathrm{W}$ for different references are also shown in Table 1 . In the upper $1000 \mathrm{~m}$, the southward transport is less than $4.6 \times 10^{6} \mathrm{~m}^{3} \mathrm{~s}^{-1}$, and maximum with a $1200 \mathrm{~m}$ reference. Thus it can be seen that neither the mean profiles nor the IGY section show a strong geostrophic transport between the Azores and Portugal. This result is independent of the reference depth chosen. The circulation in the eastern Atlantic is fed from the central Atlantic, south of the Azores.

c. Transport errors. Inaccuracies in transport computations result in part from incorrect choices of the level of no motion. This error is low in regions with a strong velocity shear in the upper ocean and small differences in the geopotential anomaly in the deeper sea and high in regions of low transports.

Errors in the computation also result from data inaccuracies. Again, following FV, the values of $0.02^{\circ} \mathrm{C}, 0.005 \%$, and $0.5 \%$ of the depth were multiplied by a random number between -1 and +1 and added to the mean temperature and salinity profiles. Transports across three sections through the subtropical gyre were computed with different reference pressures and with three altered data sets to simulate the effect of noise (Table 2). The three sections cross the subtropical gyre at the inflow south of the Azores, at the broad south component north of the Canary Islands and across the North Equatorial Current (NEC). If the reference level is replaced by $2000 \mathrm{~m}$ depth there is a difference of less than $12 \%$ in the $0-1000 \mathrm{~m}$ transport. A reference level between $500 \mathrm{~m}$ and $1000 \mathrm{~m}$ changes the transport considerably with a reversal of the flow direction for the $0-2000 \mathrm{~m}$ transport. Of course, these reference depths are unrealistic. The total transport across a section changes by less than $5 \%$ when noise-simulating alterations to the mean temperature and salinity profiles were made. 
Table 2. Integrated transport in $10^{6} \mathrm{~m}^{3} \mathrm{~s}^{-1}$ along 3 sections (denoted by " $A$ ", "B", and "C") through the subtropical gyre, relative to various reference levels. "I" denotes the transport from 0 to $1000 \mathrm{~m}$; "II", from 0 to $2000 \mathrm{~m}$; "R.S." stands for the reference surface determined by the procedure outlined in section 3 .

A: $30.5 \mathrm{~W}, 30.5 \mathrm{~N}-39.5 \mathrm{~N}$ (south of the Azores). Negative transport is to the east. (R.S. = $1160-1220 \mathrm{~m}$ ).

B: $30.5 \mathrm{~W}, 15.5 \mathrm{~N}-30.5 \mathrm{~N}$ (NEC). Negative transport is to the east. (R.S. $=1270-1360 \mathrm{~m}$ ).

C: $30.5 \mathrm{~N}, 33.5 \mathrm{~W}-12.5 \mathrm{~W}$. (meridional transport). Negative transport is to the south. (R.S. = $1100-1300 \mathrm{~m}$ ).

$\begin{array}{ccccccc}\begin{array}{c}\text { Reference } \\ {[\mathrm{m}]}\end{array} & \text { A I } & \text { A II } & \text { B I } & \text { B II } & \text { C I } & \text { C II } \\ 500 & -1.4 & +9.5 & +2.0 & -6.5 & -1.9 & +6.5 \\ 750 & - & - & 10.3 & +9.9 & -9.2 & -8.0 \\ 800 & -6.6 & -0.8 & - & - & - & - \\ 1000 & -9.7 & -7.1 & 11.8 & 13.0 & -10.9 & -11.5 \\ \text { R.S. } & -11.7 & -10.7 & 11.1 & 11.2 & -10.6 & -10.7 \\ 1300 & -12.2 & -12.0 & - & - & - & - \\ 1500 & -12.9 & -13.4 & 10.1 & 9.6 & -9.7 & -9.1 \\ 1750 & -13.0 & -13.6 & - & - & -10.4 & -10.5 \\ 2000 & -13.0 & -13.6 & 11.0 & 11.3 & -11.1 & -11.2 \\ 2500 & -10.9 & -9.5 & 10.1 & 10.4 & -11.6 & -12.8 \\ 3000 & -6.8 & -1.4 & 10.5 & 10.1 & - & - \\ \text { R.S. } & -11.5^{*} & -10.6^{*} & 11.2^{*} & 11.4^{*} & -10.8^{*} & -11.8^{*} \\ \text { R.S. } & -11.5^{*} & -10.6^{*} & 10.7^{*} & 10.8^{*} & -10.2^{*} & -10.0^{*} \\ \text { R.S. } & -11.5^{*} & -10.5^{*} & 11.9^{*} & 11.7^{*} & -10.8^{*} & -11.0^{*}\end{array}$

*These are transports derived from altered temperature and salinity profiles to simulate the effect of noise.

It seems that a total mean transport of $11 \times 10^{6} \mathrm{~m}^{3} \mathrm{~s}^{-1}$ is credible for the subtropical gyre with an estimated maximum error of $15 \%$ caused by the uncertainty in the choice of a reference level and data noise.

The error in the transport between one station pair is greater than that of a multi-station section. An uncertainty of $0.5 \times 10^{6} \mathrm{~m}^{3} \mathrm{~s}^{-1}$ or less in the $0-1000 \mathrm{~m}$ transport and an uncertainty of $0.6 \times 10^{6} \mathrm{~m}^{3} \mathrm{~s}^{-1}$ or less in the $0-2000 \mathrm{~m}$ transport were found at 45 station pairs studied. The influence of the choice of a reference depth on the transport between a station pair is greater than the error due to data noise. For the 0-1000 m transport the greatest difference found was $1.3 \times 10^{6} \mathrm{~m}^{3} \mathrm{~s}^{-1}$ if the reference was replaced by $1500 \mathrm{~m}$ but $90 \%$ of the cases studied showed differences of less than $0.5 \times 10^{6} \mathrm{~m}^{3} \mathrm{~s}^{-1}$. The greatest difference for the $0-2000 \mathrm{~m}$ transport was $2.6 \times 10^{6} \mathrm{~m}^{3} \mathrm{~s}^{-1}$.

The differences between the $0-1000 \mathrm{~m}$ and $0-2000 \mathrm{~m}$ transports are small and comparable to the noise. Thus the transport below $1000 \mathrm{~m}$ was not analyzed in this study. Readers interested in the deeper flow in this general area should consult Saunders (1982). 


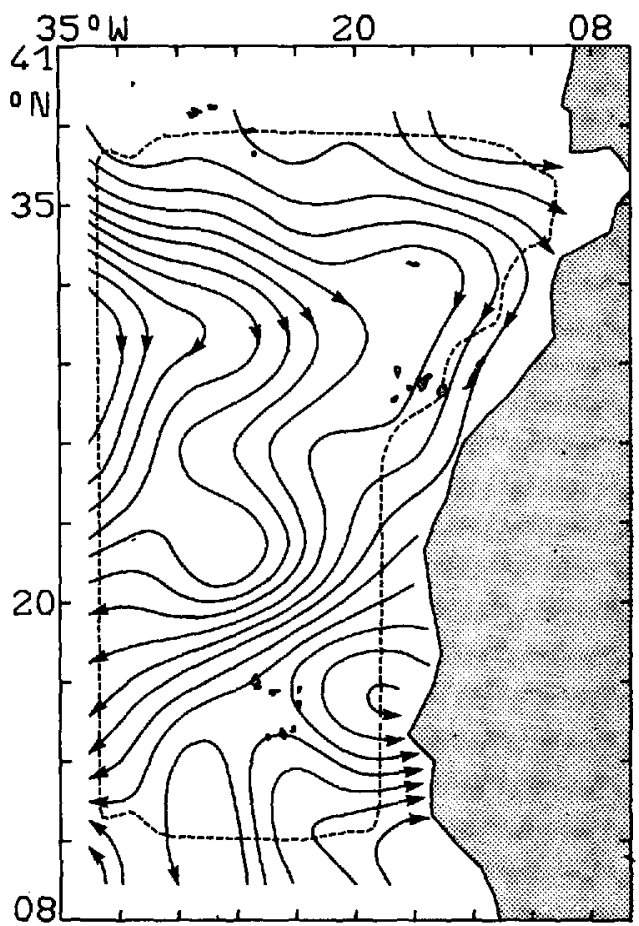

Figure 8. Integrated volume transport $(0$ to $200 \mathrm{~m})$ from mean density profiles with the reference shown in Figure 6. Each flow line represents $0.5 \times 10^{6} \mathrm{~m}^{3} \mathrm{~s}^{-1}$.

d. Transport in the upper $800 \mathrm{~m}$. Nearly half of the transport of the layer $0-800 \mathrm{~m}$ is carried in the upper $200 \mathrm{~m}$ (Fig. 8). Each streamline represents $0.5 \times 10^{6} \mathrm{~m}^{3} \mathrm{~s}^{-1}$. The contours were formed by objective analysis. The field between the border of the figure and the broken line is a region where the errors are larger than $0.5 \times 10^{6} \mathrm{~m}^{3} \mathrm{~s}^{-1}$. The transport near the African coast between $26 \mathrm{~N}$ and $20 \mathrm{~N}$ is carried out mainly in the upper $200 \mathrm{~m}$. The water from the Canary Current leaves the coastal region north of $20 \mathrm{~N}$ and crosses the $35^{\circ}$ meridian at $14 \mathrm{~N}$. The transport in the $200-800 \mathrm{~m}$ layer (Fig. 9), however, shows strong circulation in the subtropical Atlantic west of $20 \mathrm{~W}$ and weaker transport near the coast. All the flow lines leave north of $20 \mathrm{~N}$. This means that the gyre is located more to the north in the deeper ocean. Again, the contours were prepared by objective analysis with each streamline representing $1 \times 10^{6} \mathrm{~m}^{3} \mathrm{~s}^{-1}$. The error boundary of $1 \times 10^{6} \mathrm{~m}^{3} \mathrm{~s}^{-1}$ lies near the coastline and is not marked. In this figure the $4000 \mathrm{~m}$ topography is shown by a broken line.

The distribution of data from the tropics is not uniform over the seasons. There is a winter-spring bias. Because of the seasonal variation of the strength of the North Equatorial Counter Current, the transports show no clear picture in this region.

An interesting feature is the gyre found at $22 \mathrm{~N} 26 \mathrm{~W}$, which is also seen in the transports in the upper $200 \mathrm{~m}$ and in the layer betwen $200 \mathrm{~m}$ and $800 \mathrm{~m}$. In addition 


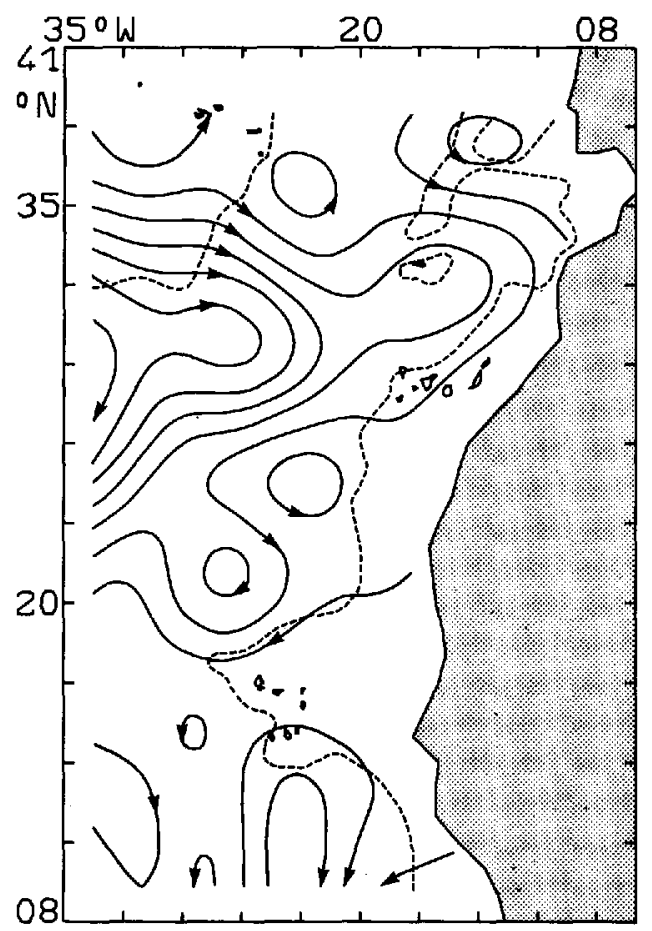

Figure 9. Integrated volume transport $(200 \mathrm{~m}$ to $800 \mathrm{~m}$ ) from mean density profiles with the reference shown in Figure 6. Each flow line represents $10^{6} \mathrm{~m}^{3} \mathrm{~s}^{-1}$. The dashed line is the $4000 \mathrm{~m}$ depth contour.

Dantzler (1977) found a region of relatively high eddy potential energy density between $18 \mathrm{~N}$ and $22 \mathrm{~N}$, and between $18 \mathrm{~W}$ and $26 \mathrm{~W}$, and Emery (1983) found large standard deviations in temperature at $400 \mathrm{~m}$ and in the $T S$-inferred dynamic topography in this area. A look at the bathymetry of this area seems worthwhile (Fig. 9). South of this eddy, one finds the Cape Verde Islands and the Cape Verde Ridge, extending westward. This is suggestive of a possible topographic influence.

However, this is the region with lowest data coverage. The square $20-23 \mathrm{~N}, 23-26 \mathrm{~W}$ contains only one profile and three of the neighboring squares contain less than five good profiles. Thus this feature should be regarded with great caution and more data are needed for a description.

\section{Currents from the F.S. Meteor sections}

The CTD profiles from the F.S. Meteor cruise in March-April, 1982 and reference depths determined from the historic data, were used to calculate transports in the eastern North Atlantic. The integrated transport from 5 or $10 \mathrm{~m}$ depth, where the CTD registration began, down to $1000 \mathrm{~m}$ is presented in Figure 10 with each flow line 


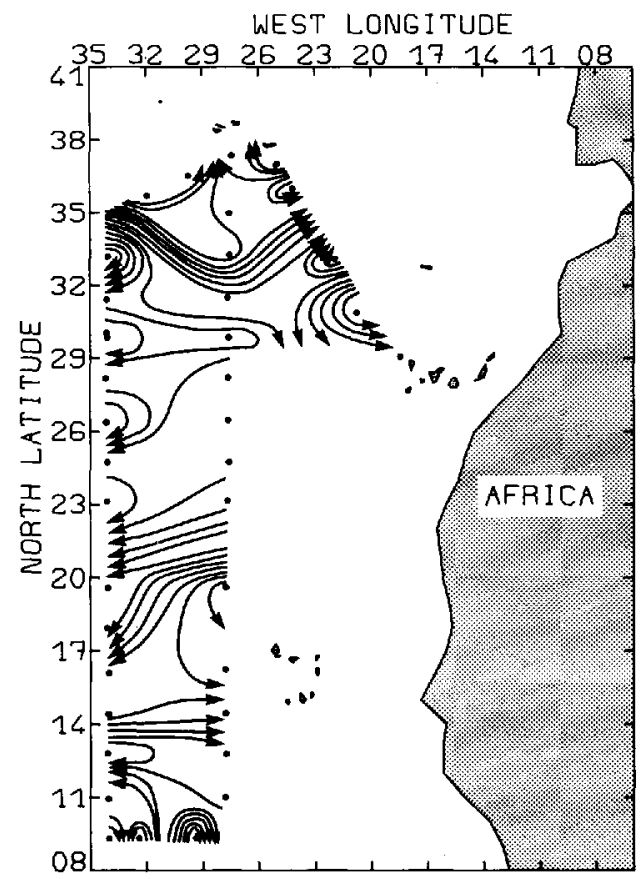

Figure 10. Integrated volume transport ( 5 or $10 \mathrm{~m}$ to $1000 \mathrm{~m}$ ) from the F.S. Meteor cruise no. 60 data in March-April, 1982 with the reference shown in Figure 5. Each flow line represents $10^{6} \mathrm{~m}^{3} \mathrm{~s}^{-1}$.

representing $10^{6} \mathrm{~m}^{3} \mathrm{~s}^{-1}$. A strong narrow current, south of the Azores enters the region between $33^{\circ} 20^{\prime}$ and $35 \mathrm{~N}$ with $11 \times 10^{6} \mathrm{~m}^{3} \mathrm{~s}^{-1}$ and flows southeastward up to the longitude of the Azores. Its northward turn when reaching deeper water (note the $4000 \mathrm{~m}$ depth contour in Fig. 9) is speculative. Another interpretation is that most of this flow continues southeastward, and a great anticyclonic eddy exists between Madeira and the Azores.

Käse and Siedler (1982) present a strong, narrow flow southeast of the Azores. This flow was determined from geostrophic computations and satellite-tracked drift buoys in a region mid-way between the Azores and the Canary Islands. The strength was computed to be of the order $10 \times 10^{6} \mathrm{~m}^{3} \mathrm{~s}^{-1}$. The position of the maximum horizontal gradient of surface temperature was established from observations made west of their CTD survey area. This surface temperature front is not consistent with the location of the geostrophic flow computed herein from the density data of F.S. Meteor.

Essentially, these transports are in agreement with those computed from historic data. In particular, the transport between $200 \mathrm{~m}$ and $800 \mathrm{~m}$ shows a westward outflow along a more northern zone than was the case in the surface layer. The same result was found in the various transports computed from the historic data. In this case there is no 


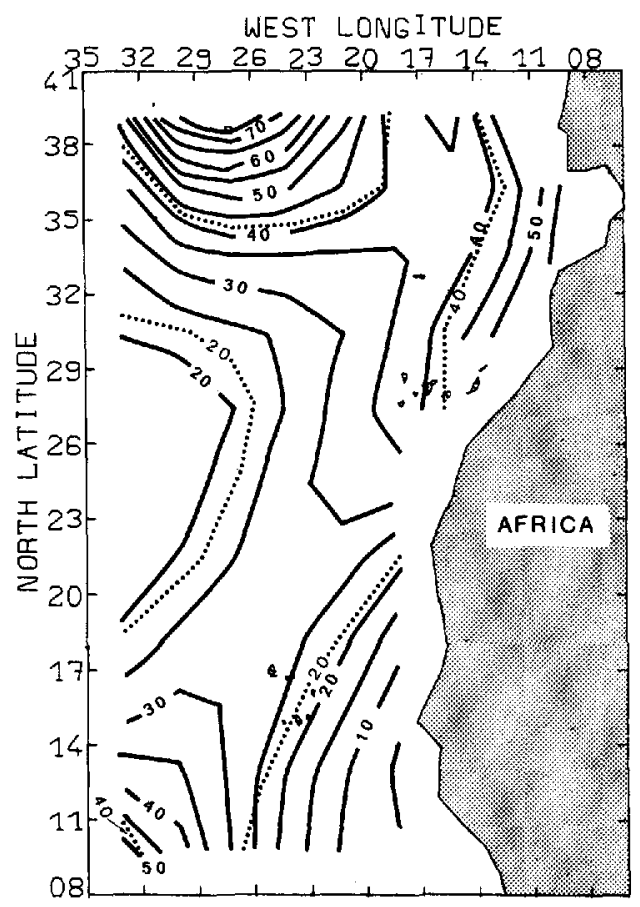

Figure 11. Smoothed potential vorticity $\times 10^{14} \mathrm{~m}^{-1} \mathrm{~s}^{-1}$ on the isopycnal surface $26.5 \mathrm{~kg} \mathrm{~m}^{-3}$. Dashed lines represent potential vorticity derived from the noise simulating data set.

visible difference between the mean transport field and the spring 1982 transport field from the F.S. Meteor.

\section{Potential vorticity}

In recent years, there have been studies which dealt with potential vorticity as an indicator of water masses and currents. Luyten et al. (1983) presented a model which had the deeper layers directly driven by Ekman pumping in the outcropping area, but was geostrophic and potential-vorticity-conserving elsewhere. McDowell et al. (1982) have shown that for quasi-geostrophic ocean dynamics, where the horizontal velocity is nearly nondivergent, and for baroclinic flow with horizontal scales much larger than the Rossby radius (i.e., small relative vorticity), the potential vorticity $q$ can be determined from hydrographic measurements of the potential density $\bar{\rho}$ (in $10^{3}$ $\mathrm{kg} \mathrm{m}^{-3}$ ) alone. In this case,

$$
\bar{q} \approx \frac{f}{\rho_{0}} \frac{\partial \bar{\rho}}{\partial z}
$$

where $f$ is the Coriolis parameter and $z$ is the vertical coordinate (positive downward). 


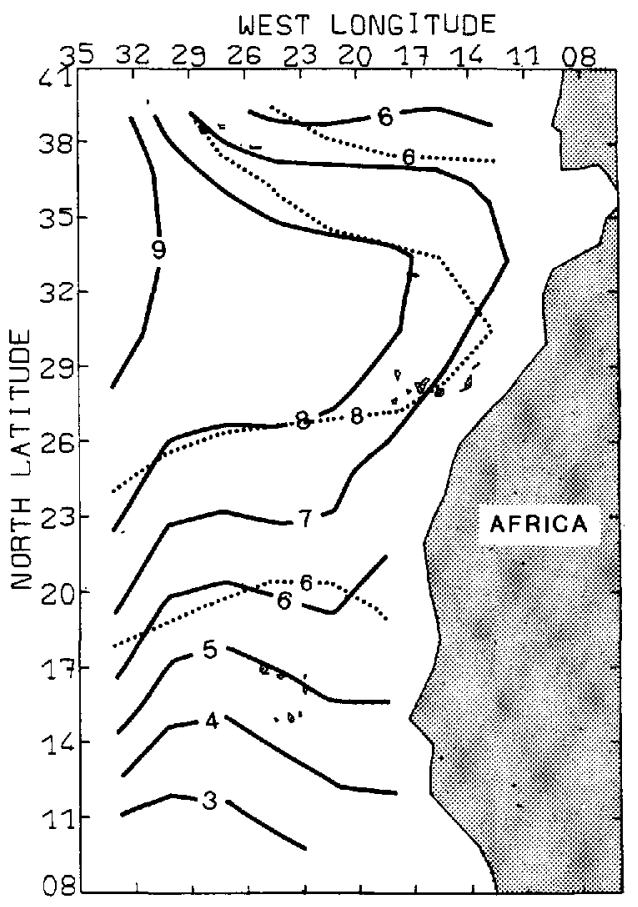

Figure 12. Smoothed potential vorticity $\times 10^{14} \mathrm{~m}^{-1} \mathrm{~s}^{-1}$ on the isopycnal surface $27.1 \mathrm{~kg} \mathrm{~m}^{-3}$. Dashed lines represent potential vorticity derived from the noise simulating data set.

Using this relationship, potential vorticity was computed from the density profiles derived from historic hydrographic data. The profiles were re-grided at $5 \mathrm{~m}$ intervals with cubic splines and then finite differenced over $10 \mathrm{~m}$ intervals. Maps of potential vorticity on density surfaces were produced for the $\sigma_{\theta}$ surfaces $26.5,26.8$ and 27.1 $\mathrm{kg} \mathrm{m}^{-3}$, similar to those of Sarmiento et al. (1982). The resultant potential vorticities were very noisy because of the small interpolation depth and because the mean profiles were produced from data from different years.

McCartney (1982) showed that there can be temporal variation in the potential vorticity as large as the spatial variation, and, therefore, it would be desirable to have a synoptic picture. In order to overcome this problem and to reduce the error due to the small interpolation depths, smoothed maps were made by fitting double Chebyshev series of degree 3 to the potential vorticity. Again, FV's noise test was made with the same amplitudes as used before. The values of the potential vorticities changed but the overall picture was essentially the same. In Figures 11 and 12, two isotrophes of the noise simulation data are shown.

Smoothed potential vorticity on the $\sigma_{\theta}=26.5$ (midhalocline) surface (Fig. 11) predominantly shows that the isotrophes ( $\bar{q}$ constant) run in the same general direction as the mean flow; i.e., the anticyclonic gyre between $35 \mathrm{~N}$ and $17 \mathrm{~N}$ is revealed. 
Northward of $35 \mathrm{~N}$, a high vorticity region is seen, which is not congruent with the mean flow. The depth of the $\sigma_{\theta}$ surface in this region is $25-50 \mathrm{~m}$ and constitutes a shoaling of the surface, which lies mostly in the 100-250 m range. Also, a northward decrease in $q$ on the equator side of the gyre can be seen, similar to the situation found by McDowell et al. (1982). They have shown, that this area is potentially baroclinically unstable.

The 26.8-surface $(80-400 \mathrm{~m})$ is dominated by nearly uniform potential vorticity and will not be shown here. This is a layer of homogenization predicted by theory for a stably stratified ocean at depths greater than those of direct wind-induced stress or penetrative cooling (Rhines and Young, 1982).

The 27.1-surface (300-625 m) is located just above the base of the wind-spun gyre (Fig. 12). The potential vorticity contours are again gyre-like but are situated more to the north than is the case with the 26.5-surface and without as much southward extension as is the case with the geostrophic flow contours.

Essentially, it is found that the geostrophic flow is consistent with the distribution of the potential vorticity, which is independent of reference depth.

\section{Discussion}

At first glance it seems that a transport study using the classical method is antiquated. But the hopes for a more reliable reference level from inverse theory or absolute velocities from the $\beta$-spiral method have not been entirely realized yet. It is perhaps more realistic to assume a low-velocity layer instead of a permanent level of no motion. The velocity in the Warm Water Sphere is large compared to the velocities near plausible reference depths. It is therefore useful to employ the classical method in addition to the new methods to at least gain an insight into the mass transport system of the subtropical eastern North Atlantic.

The transports studied were limited to those in the upper $1000 \mathrm{~m}$ because data noise produced large uncertainties in the deeper transports. The overall picture in the geostrophic flow is consistent with the distribution of potential vorticity. It seems that the transports computed in this study are a plausible representation of the mean circulation in the eastern North Atlantic.

Acknowledgments. This work was supported by the Deutsche Forschungsgemeinschaft, Bonn, Federal Republic of Germany (FRG). I would like to acknowledge the assistance of the data processing staff of the Marine Physics Group at the Institut für Meereskunde, Kiel, FRG. I want to thank C. Brückner for preparing the figures. This paper was much improved after careful reading by J. M. Price, for whose comments and corrections I am grateful.

\section{REFERENCES}

Behringer, D. and H. Stommel. 1980. The beta spiral in the North Atlantic subtropical gyre. Deep-Sea Res., 27 A, 225-238.

Dantzler, H. L., Jr. 1977. Potential energy maxima in the tropical and subtropical North Atlantic. J. Phys. Oceanogr., 7, 512-519. 
Defant, A. 1941. Die absolute Topographie des physikalischen Meeresniveaus und der Druckflächen, sowie die Wasserbewegungen im Atlantischen Ozean. Deutsche Atlantische Exped. "Meteor" 1925-1927, Vol. 6, Part 2, No. 5, 191-260.

Dietrich, G., K. Kalle, W. Krauss and G. Siedler. 1980. General Oceanography (translated by S. and H.U. Roll) Wiley, New York, NY, $626 \mathrm{pp}$.

Ekman, V. W. 1923. Über Horizontalzirkulation bei winderzeugten Meereströmungen. Arkiv för Matematik, Astronomi och Fysik, 34, 423-430.

Emery, W. J. 1983. On the geographical variability of the upper level mean and eddy fields in the North Atlantic and North Pacific. J. Phys. Oceanogr., 13, 269-291.

Fiadeiro, M. E. and G. Veronis. 1982. On the determination of absolute velocities in the ocean. J. Mar. Res., 40 (Suppl.), 159-192.

1983. Circulation and Heat Flux in the Bermuda Triangle. J. Phys. Oceanogr., 13, $1158-1169$.

Fomin, L. M. 1964. The Dynamical Method in Oceanography. Elsevier Oceanogr. Series, 212 pp.

Hellerman, S. 1980. Charts of the variability of the wind stress over the tropical Atlantic. Deep-Sea Res., GATE Suppl., 26, 63-75.

Hiller, W. and R. H. Käse. 1983. Objective Analysis of the Hydrographic Data sets from Mesoscale Surveys. Ber. Inst. für Meereskunde, Kiel, 116, $78 \mathrm{pp}$.

Jacobsen, J. P. 1929. Contribution to the hydrography of the North Atlantic: The "Dana" Expedition 1920-22. Oceanographical Reports edited by the Dana-Committee, 1, 3, 98 pp.

Käse, R. H. and G. Siedler. 1982. Meandering of the subtropical front south-east of the Azores. Nature, 300, 245-246.

Keffer, T. and P. Niiler. 1982. Eddy convergence of heat, salt, density and vorticity in the subtropical North Atlantic. Deep-Sea Res., 29, 201-216.

Luyten, J. and H. Stommel. 1982. Recirculation reconsidered. J. Mar. Res., 40 (Suppl.), 407-426.

Luyten, J., J. Pedlosky and H. Stommel. 1983. The ventilated thermocline. J. Phys. Oceanogr., 13, 292-309.

McCartney, M. S. 1982. The subtropical recirculation of Mode Waters. J. Mar. Res., 40 (Suppl.), 427-464.

McDowell, S., P. Rhines and T. Keffer. 1982. North Atlantic potential vorticity and its relation to the general circulation. J. Phys. Oceanogr., 12, 1417-1436.

Rhines, P. B. and W. Young. 1982. Homogenization of potential vorticity in planetary gyres. J. Fluid Mech., 122, 347-367.

Roemmich, D. 1981. Circulation of the Carribean Sea: A well resolved inverse problem. J. Geophys. Res., 86, 7993-8005.

Sarmiento, J. L., C. G. Rooth and W. Roether. 1982. The North Atlantic tritium distribution in 1972. J. Geophys. Res., 87, 8047-8056.

Saunders, P. M. 1982. Circulation in the eastern North Atlantic. J. Mar. Res., 40 (Suppl.), 641-657.

Schumacher, A. 1940. Monatskarten der Oberflächenströmungen im Nordatlantischen Ozean (5S-50N). Ann. d. Hydr. u. Marit. Meterorol., 68, 109 pp.

Siedler, G. and L. Stramma. 1983. The applicability of the T/S method to geopotential anomaly computations in the Northeast Atlantic. Oceanol. Acta, 6, 167-172.

Stommel, H., P. Niiler and D. Anati. 1978. Dynamic topography and recirculation of the North Atlantic. J. Mar. Res., 36, 449-468.

Stommel, H. and F. Schott. 1977. The beta spiral and the determination of the absolute velocity field from hydrographic station data. Deep-Sea Res., 24, 325-329. 
Sverdrup, H. U., U. W. Johnson and R. H. Fleming. 1942. The Oceans, Prentice Hall, 1087 pp.

Worthington L. V. 1976. On the North Atlantic Circulation. John Hopkins Oceanogr. Studies, $6,110 \mathrm{pp}$.

Wunsch, C. 1977. Determining the general circulation of the oceans: A preliminary discussion. Science, 196, 871-875.

1978. The North Atlantic circulation west of $50 \mathrm{~W}$ determined by inverse methods. Rev. Geophys. Space Phys, 16, 583-620.

Wunsch, C. and B. Grant. 1982. Towards the general circulation of the North Atlantic Ocean. Prog. in Oceanogr., 11, 1-59.

Wüst, G. 1936. Die Stratosphäre des Atlantischen Ozeans. Deutsche Atlantische Exped. "Meteor" 1925-1927, Vol. 6, Part 1, 109-288. 